\title{
PENINGKATAN PENGETAHUAN DAN KETERAMPILAN KADER KESEHATAN MELALUI PENYULUHAN DAN PELATIHAN TEKNIK KOMPLEMENTER PIJAT OKSITOSIN
}

\author{
Ranny Septiani ${ }^{1^{*}}$, M.Ridwan ${ }^{2^{*}}$ \\ ${ }^{1,2}$ Prodi Kebidanan Metro, Poltekkes Tanjungkarang, Indonesia \\ ${ }^{1}$ rannyseptiani@poltekkes-tjk.ac.id, ${ }^{2}$ ridwan@poltekkes-tjk.ac.id
}

\begin{abstract}
ABSTRAK
Abstrak Praktik melakukan pijat oxytosin dalam rangka peningkatan produksi Air Susu [bu (ASI) untuk kesehatan bayi dan anak dan pemberian makan yang baik dan tepat sangat penting untuk kelangsungan hidup, pertumbuhan, perkembangan, kesehatan dan gizi bayi dan anak batita.Metode yang digunakan (1) Pre-post tes (2) Ceramah dan tanya jawab pentingnya pijat oxytosin, (3) Demonstrasi dan simulasi pijat oksitosin,(4) redemonstrasi oleh kader.Hasil dari pelaksanaan kegiatan berdasarkan pre dan post tes terjadi peningkatan pengetahuan kader tentang pijat oksitosin dari rata-rata 42 menjadi 75. Dapat disimpulkan bahwa pada prinsipnya pelatihan telah berhasil menambah pengetahuan dan ketrampilannya tentang tekhnik komplementer: Pijat Oxytosin pada ibu menyusui
\end{abstract}

Kata Kunci: Pijat Oksitosin, Menyusui

\begin{abstract}
The practice of doing oxytosin massage in order to increase the production of breast milk for infant and child health and good and proper feeding is very important for the survival, growth, development, health and nutrition of infants and toddlers. Methods used (1) Pre-post-tests (2) Lectures and discussion about the importance of oxytocin massage, (3) Demonstration and simulation of oxytocin massage, (4) re-demonstration by health cadres. The results of the implementation of activities based on pre and post-tests occur increasing health cadres knowledge about oxytocin massage from the average averaged 42 to 75 . It can be concluded that in principle the training has succeeded in increasing knowledge and skills about complementary techniques: Oxytocin massage in breastfeeding mothers.
\end{abstract}

Keywords: Oxytocin Massage, Breastfeeding

\section{A. LATAR BELAKANG}

Kelurahan Hadimulyo Barat Kecamatan Metro Pusat, Kota Metro merupakan wilayah binaan Politeknik Kesehatan Tanjungkarang, yang telah berlangsung sejak tahun 2015. Berbagai upaya kesehatan yang dilakukan di kelurahan Hadimulyo Barat oleh Poltekkes Tanjungkarang melalui Jurusan atau Program Studi yang ada telah dilaksanakan secara berkesinambungan, baik melalui upaya promotif dan preventif terus ditingkatkan, dengan tidak mengeyampingkan upaya kurative serta rehabilitatif. Peningkatan upaya kesehatan dari ke 4 bidang tersebut, dengan harapan derajat kesehatan masyarakat pada setiap tahapan kehidupan, baik secara individu, keluarga maupun kelompok masyarakat. Pembangunan kesehatan diarahkan untuk mencapai sasaran seperti 
meningkatnya umur harapan hidup, menurunnya angka kematian bayi (AKB), menurunnya angka kematian ibu (AKI), dan menurunnya prevalensi gizi kurang pada balita, serta menurunnya angka kesakitan pada umumnya (Ardianti, Wibisono, \& Jumiati, 2015). Stunting adalah masalah kurang gizi kronis yang disebabkan oleh asupan gizi yang kurang dalam waktu cukup lama akibat pemberian makanan yang tidak sesuai dengan kebutuhan gizi (Mayasari et al., 2018). Riset Kesehatan Dasar 2013 mencatat prevalensi stunting nasional mencapai 37,2 persen, meningkat dari tahun 2010 (35,6\%) dan 2007 (36,8\%) (Pilaria \& Sopiatun, 2017), (Asih, 2018). Artinya, pertumbuhan tak maksimal diderita oleh sekitar 8 juta anak Indonesia, atau satu dari tiga anak Indonesia. Prevalensi Stunting di Indonesia lebih tinggi dari pada negara-negara lain di Asia Tenggara, seperti Myanmar (35\%), Vietnam (23\%), dan Thailand (16\%) (Kesehatan RI, 2016). Praktik melakukan pijat oxytosin dalam rangka peningkatan produksi Air Susu Ibu (ASI) untuk kesehatan bayi dan anak dan pemberian makan yang baik dan tepat sangat penting untuk kelangsungan hidup, pertumbuhan, perkembangan, kesehatan dan gizi bayi dan anak batita (Bukhori, 2016). Hasil Riskesdas dan observasi lapangan, terjadinya gangguan pertumbuhan khususnya pada kelompok bayi dan anak batita hal ini dikarenakan belum optimalnya pemberian ASI sebagai sumber utama makanan bagi bayi. Permasalahan ini dilatarbelakangi karena kurangnya produksi ASI ibu menyusui dan melalui kegiatan penyuluhan dan pelatihan praktik pijat oxytosin yang diberikan kepada kader kesehatan diharapkan kader mampu mentransfer pengetahuan dan keterampilan yang telah dilatih dengan cara mengajarkan pada ibu-ibu menyusui di wilayah kerjanya untuk melakukan pijat oksitosin.

Pijat ASI merupakan salah satu solusi untuk mengatasi ketidaklancaran produksi ASI. Pijat ASI adalah pemijatan pada sepanjang tulang belakang (vertebrae) sampai tulang costae kelima-keenam dan merupakan usaha untuk merangsang hormon prolaktin dan oksitosin setelah melahirkan (Setyowati, Andayani, \& Widayati, 2015). Pijat ASI yang sering dilakukan dalam rangka meningkatkan ketidaklancaran produksi ASI adalah pijat oksitosin. Pijat oksitosin, bisa dibantu pijat oleh ayah atau nenek bayi. Pijat oksitosin ini dilakukan untuk merangsang refleks oksitosin atau reflex let down. Selain untuk merangsang refleks let down manfaat pijat oksitosin adalah memberikan kenyamanan pada ibu, mengurangi bengkak (engorgement), mengurangi sumbatan ASI, merangsang pelepasan hormon oksitosin, mempertahankan produksi ASI ketika ibu dan bayi sakit.

\section{B. METODE PELAKSANAAN}

Kegiatan Pengabdian Kepada Masyarakat (Pengabmas) yang dilaksanakan di Posyandu Kenanga Kelurahan Hadimulyo Barat Kecamatan Metro Pusat, Kota Metro dengan tema : "Melalui Penyuluhan 
dan Pelatihan Kader Posyandu dan Ibu Menyusui, kita wujudkan bayi sehat sebagai generasi yang berkualitas".

Jenis Kegiatan pengabdian kepada masyarakat (Pengabmas) yang dilaksanakan di Posyandu Asoka Kelurahan Hadimulyo Barat Kecamatan Metro Pusat, Kota Metro ini, meliputi:

1. Penyuluhan Kader Posyandu dan ibu menyusui tentang tekhnik Komplementer: Pijat Oxytosin.

2. Pelatihan Kader tentang tekhnik Komplementer: Pijat Oxytosin

3. Pelatihan ibu menyusui tentang tekhnik Komplementer: Pijat Oxytosin

Langkah-langkah melakukan pijat ASI dengan metode oksitosin sebagai berikut (Setyowati et al., 2015), (Maita, 2016), (Buhari, 2018), :

1. Melepaskan baju ibu bagian atas.

2. Ibu miring ke kanan maupun kekiri, lalu memeluk bantal, namun ada dua posisi alternatif, yaitu: boleh telungkup di meja.

3. Memasang handuk.

4. Melumuri kedua telapak tangan dengan minyak atau baby oil.

5. Memijat sepanjang kedua sisi tulang belakang ibu dengan menggunakan dua kepala tangan, dengan ibu jari menunjuk ke depan. Area tulang belakang leher, cari daerah dengan tulang yang paling menonjol, namanya processus spinosus/cervical vertebrae 7 .

6. Menekan kuat-kuat kedua sisi tulang belakang membentuk gerakangerakan melingkar kecil-kecil dengan kedua ibu jarinya.

7. Pada saat bersamaan, memijat kedua sisi tulang belakang kearah bawah, dari leher kearah tulang belikat, selama 2-3 menit.

8. Mengulangi pemijatan hingga 3 kali.

9. Membersihkan punggung ibu dengan waslap air hangat dan dingin secara bergantian

Sasaran kegiatan pengabdian kepada masyarakat (Pengabmas) adalah Kader Posyandu dan Ibu Menyusui di wilayah Posyandu Asoka Kelurahan Hadimulyo Barat Kecamatan Metro Pusat, Kota Metro. Metode yang digunakan dalam pelaksanaan kegiatan Pengabdian kepada masyarakat (Pengabmas) yang dilaksanakan di Posyandu Asoka Kelurahan Hadimulyo Barat Kecamatan Metro Pusat, Kota Metro ini adalah :

1. Ceramah dan tanya jawab tentang pentingnya tekhnik komplementer: Pijat Oxytosin.

2. Demonstrasi dan simulasi tentang tekhnik Komplementer : pijat Oxytosin dalam meningkatkan produksi ASI bagi ibu yang menyusui bayinya. Tujuan alkhirnya kesehatan dan pertumbuhan serta perkembangan terhadap bayi dapat berlangsung secara optimal.

3. Redemonstrasi oleh Kader Posyandu tentang tekhnik komplementer:Pijat Oxytosin kepada ibu menyusui di wilayahnya.

4. Pelaksanaan pre dan pos test terhadap Kader Posyandu sebelum diberikan materi tekhnik komplementer:Pijat Oxytosin. 


\section{HASIL DAN PEMBAHASAN}

Kegiatan Pengabdian kepada masyarakat yang dilaksanakan (Pengabmas) di Posyandu Asoka kelurahan Hadimulyo Barat Metro Pusat, Kota Metro dengan hasil sebagai berikut:

1. Pelaksanaan kegiatan berjalan dengan lancar sesuai dengan rencana .

2. Dosen yang melaksanakan kegiatan berjumlah 4 orang

3. Mahasiswa yang diikut sertakan berjumlah 4 orang, semuanya tingkat IV Program D IV Prodi Kebidanan Metro.

4. Kader Posyandu Asoka Kelurahan Hadimulyo Barat sebanyak 5 orang yang ada.

5. Ibu menyusui yang hadir berjumlah 6 orang

Kegiatan ini berlangsung secara interaktif, berjalan dengan baik, tertib dan lancar.

1. Pada hari pertama tanggal 13 Desember 2017 pelatihan diikuti oleh 5 orang Kader Posyandu Asoka. Semua peserta mengikuti pelatihan dengan aktif hingga kegiatan berakhir. Keaktifan peserta ditandai dengan banyaknya pertanyaan yang diajukan oleh peserta, dan saat pelatihan semua memperagakan pemijatan pada tubuh/punggung dengan baik dan benar.

2. Pada hari kedua tanggal 15 Desember 2017 kegiatan pelatihannya adalah Kader Posyandu yang telah dilatih pada hari pertama sebanyak 8 orang. Masing-masing kader membawa ibu menyusui, kemudian masing-masing Kader memperagakan/melakukan cara pemijatan pada punggung ibu dengan tekhnik komplementer. Adapun posisi ibu ada yang dilakukan duduk santai, mereka ada yang duduk diatas kursi pijat, sedangkan lainnya duduk di kursi biasa. Dosen bersama mahasiswa melakukan pengamatan kepada Kader, kemudian membetulkan saat kader melakukan pemijatan salah atau kurang tepat. Dosen memberi motivasi kepada ibu agar mau pijat oxytosin guna meningkatkan produksi ASI nya. Sebelum kader melakukan pijat kepada ibu menyusui terlebih dahulu mendemonstrasikan pijat dengan phantom dihadapan ibu-ibu.
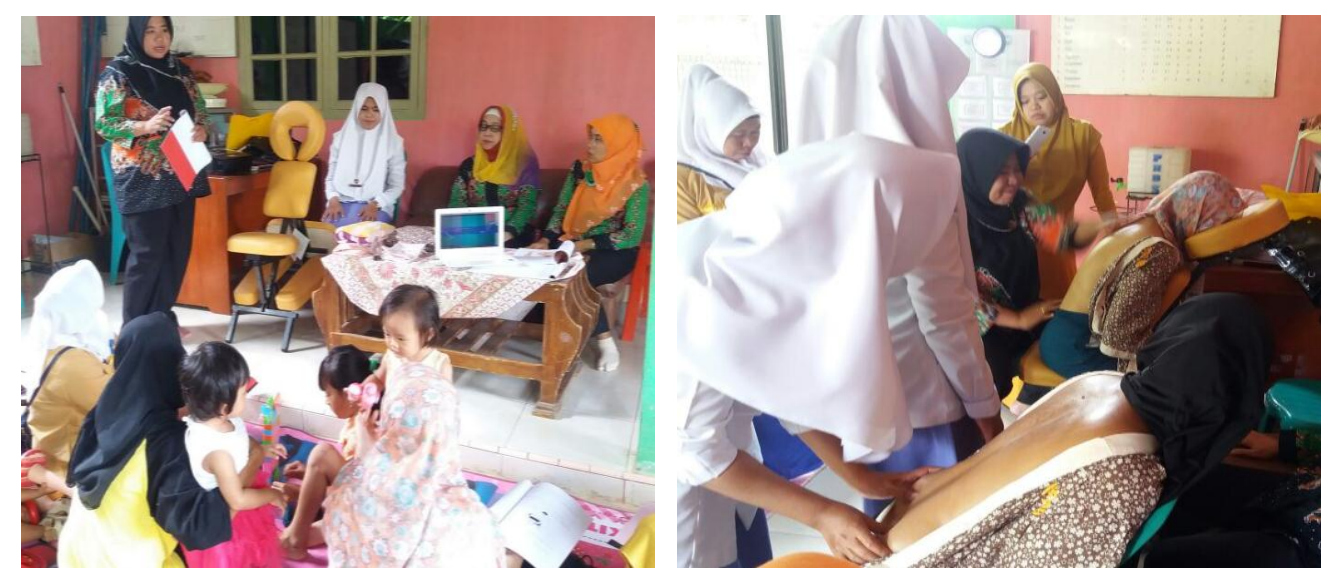

Gambar 1. Kegiatan Ceramah dan demonstrasi Pijat Oksitosin 
3. Penilaian sebelum dan sesudah Pelatihan

Nilai Rata-Rata Pre dan Post Test Pengetahuan Kader tentang Pijat Oxytosin, di Posyandu Asoka Hadimulyo Barat sesuai Tabel 1 berikut:

Tabel 1. Daftar Nilai Pre dan Post Test Peserta (Kader Posyandu)

\begin{tabular}{llcc}
\hline No & Nama & Nilai Pre & Nilai Post \\
\hline 1 & Ny. Aris & 40 & 80 \\
\hline 2 & Ny. Yuniarti & 50 & 75 \\
\hline 3 & Ny. Sri Katun & 30 & 70 \\
\hline 4 & Ny. Lestari & 50 & 80 \\
\hline 5 & Ny. Isnanik & 40 & 70 \\
\hline \multicolumn{2}{c}{ Nilai Rata-rata } & $\mathbf{4 2}$ & $\mathbf{7 5}$ \\
\hline
\end{tabular}

Berdasarkan Tabel 1, perolehan nilai dari 6 orang kader Posyandu Asoka di Kel. Hadimulyo Barat didapat nilai rata-rata pre-test yaitu 42 dengan nilai minimal yaitu 30 dan nilai maksimal yaitu 50, sedangkan perolehan nilai rata-rata post-test yaitu 75 dengan nilai minimal yaitu 70 dan nilai maksimal yaitu 80 .

Hasil pelatihan Kader tentang tekhnik Komplementer: Pijat Oxytosin pada Ibu Menyusui memperlihatkan adanya peningkatan nilai pengetahuannya dan ketrampilannya. Dapat disimpulkan bahwa pada prinsipnya pelatihan telah berhasil menambah pengetahuan dan ketrampilannya tentang tekhnik komplementer: Pijat Oxytosin pada ibu menyusui.

Hal-hal yang ditemui sebagai kendala saat pelaksanaan kegiatan, adalah :

1. Kesibukan kader. Sebagian besar Kader Posyandu pekerjaan pokoknya sebagai guru PAUD atau TK setempat, sehingga pelatihan baru bisa dimulai setelah kegiatan sekolahnya berakhir.

2. Waktu kegiatan antara pemberian materi oleh dosen kepada kader dengan praktik kader relatif singkat, hanya satu hari kegiatan saja, sehingga kami tidak sempat melakukan follow up untuk melakukan evaluasi lebih lanjut .

Solusi dalam pemecahan masalah tersebut, adalah :

1. Waktu pelaksanan pelatihan sebaiknya pagi hari, sehingga kader mudah menerima masukan materi pelatihan dengan baik.

2. Lamanya waktu yang digunakan untuk pelatihan sebaiknya ditambah atau mencari waktu yang tidak berbenturan dengan kegiatan lainnya

3. Kegiatan perlu dilakukan secara berkesinambungan dan periodik juga dapat dilakukan pada Posyandu yang ada di tempat lainnya 


\section{SIMPULAN DAN SARAN}

Simpulan atas kegiatan pengabdian kepada masyarakat melalui penyuluhan dan pelatihan kader tentang teknik komplementer : pijat oksitosin untuk ibu menyusui di Posyandu Asoka Kelurahan Hadimulyo Barat Kecamatan Metro Pusat Kota Metro Provinsi Lampung, antara lain (1) Meningkatnya kepedulian dosen dalam meningkatkan derajat kesehatan pada ibu-ibu menyusui, khususnya dalam melakukan tekhnik Komplementer: Pijat Oxytosin; (2) Meningkatnya pengetahuan dan ketrampilan Kader Posyandu untuk merangsang kesehatan ibu menyusui, guna mengoptimalkan pertumbuhan dan perkembangan bayinya; dan (3) Terlaksananya kegiatan pelatihan dengan baik dan semua peserta dapat mengikutinya dengan baik dari awal hingga berakhirnya pelatihan, semua bersifat kondusif dan bersemangat tinggi.

Pengabdian kepada masyarakat oleh Dosen Poltekkes Tanjungkarang Prodi Kebidanan Metro agar selanjutnya dapat dilaksanakan serupa secara berkesinambungan di setiap Posyandu, khususnya pada kader kesehatan dan ibu menyusui. Karena melalui pelatihan pijat oxitosin ini para kader dapat menjadi pioner dalam menyehatkan ibu menyusui dan bayinya. Pijat yang benar akan meningkatkan produksi ASI yang adekuat. Semoga kegiatan pelatihan ini dapat dilanjutkan pada masa yang akan datang.

\section{UCAPAN TERIMA KASIH}

Tim penulis mengucapkan terimakasih kepada Unit Pengabdian Kepada Masyarakat Poltekkes Tanjungkarang yang telah memfasilitasi kegiatan pengabdian kepada masyarakat kelurahan Hadimulyo Barat yang dilaksanakan oleh Dosen Prodi Kebidanan Metro. Lurah Kelurahan Hadimulyo Barat Kecamatan Metro Barat Kota Metro atas ijin dan dukungan dalam kegiatan ini, Peserta pelatihan kader dan ibu menyusui kelurahan Hadimulyo Barat yang telah aktif mengikuti kegiatan hingga selesai.

\section{DAFTAR RUJUKAN}

Ardianti, A. V., Wibisono, S., \& Jumiati, A. (2015). Faktor-Faktor yang Mempengaruhi Angka Harapan Hidup di Kabupaten Jember. Artikel Ilmiah Mahasiswa, 1-6.

Asih, Y. (2018). Pengaruh Pijat Oksitosin terhadap Produksi ASI pada Ibu Nifas. Jurnal Ilmiah Keperawatan Sai Betik, 13(2), 209. https://doi.org/10.26630/jkep.v13i2.931

Buhari, S. (2018). Perbandingan Pijat Oketani Dan Oksitosin Terhadap Produksi Air Susu Ibu Pada Ibu Post Partum Hari Pertama Sampai Hari Ketiga di Rumah Sakit TK II Pelamonia Makassar. Kesehatan, 2(2), 209-220.

Bukhori, B. (2016). Pengembangan Social Skill Narapidana Melalui Pelatihan Pijat. Dimas: Jurnal Pemikiran Agama Untuk Pemberdayaan, 16(1), 49. https://doi.org/10.21580/dms.2016.161.891

Kesehatan RI, K. (2016). InfoDATIN: Situasi Balita Pendek. Jakarta: Pusat Data dan Informasi. 
Maita, L. (2016). Pengaruh Pijat Oksitosin Terhadap Produksi ASI. Jurnal Penelitian Kesehatan Suara Forikes, VII, 173-175.

Mayasari, D., Indriyani, R., Ikkom, B., Kedokteran, F., Lampung, U., Kemenkes, P., ... Lampung, B. (2018). Stunting , Faktor Resiko dan Pencegahannya Stunting, Risk Factors and Prevention. Jurnal Agromedicine, 5(1), 540-545.

Pilaria, E., \& Sopiatun, R. (2017). Pengaruh Pijat Oksitosin Terhadap Produksi Asi Pada Ibu Postpartum Di Wilayah Kerja Puskesmas Pejeruk Kota Mataram Tahun 2017. Jurnal Kedokteran Yasri 26 (1).

Setyowati, H., Andayani, A., \& Widayati, W. (2015). Perbedaan Produksi ASI Pada Ibu Post Partum Setelah Pemberian Pijat Oksitosin. Soedirman Journal of Nursing, 10(3), 188-195. 